\title{
Analysis of the theoretical CVC of electromembrane systems
}

\author{
$A$ Kovalenko ${ }^{1, *}$ and $M$ Urtenov $^{1}$ \\ ${ }^{1}$ Kuban State University, St. Stavropolskaya 149, 350040 Krasnodar, Russia
}

\begin{abstract}
In a number of recent studies, the authors derived and substantiated a formula for calculating the theoretical current voltage curve (CVC) of electromembrane systems (EMS). This formula was created for the flow cell of desalination of the electrodiaysis apparatus formed by an anion exchange (AEM) and a cation exchange membranes (CEM) in the potentiodynamic mode based on the charge conservation law. In this paper, the formula for the CVC (I-V characteristic) is investigated, its physical meaning, and the contribution of various factors to the CVC are revealed. A new simplified formula is proposed for calculating CVC, stable with respect to rounding errors. The critical values of the current density were determined and the current voltage curve was divided into separate sections. In the article, we showed that for characteristic values of the average flow rate of the electrolyte solution, the initial concentration in all sections of the CVC, the contribution of the convective current is small. The main role belongs to the electromigration (ohmic) current, especially in the overlimiting sections of the current - voltage curve. The contribution of the diffusion current in limiting and underlimiting sections is quite significant, although less than the ohmic current.
\end{abstract}

\section{Introduction}

The current-voltage curve $(\mathrm{CVC})$ is the most important integral characteristic of ion transport in electromembrane systems (EMS). The role of the CVC is especially important in the study of the overlimiting current density flows. A research of the experimental CVC in the overlimiting current mode, carried out by the methods of Fourier analysis [1], wavelet analysis [2], and dynamic chaos methods [3], shows a complex, unsteady and unstable behavior of the CVC. However, a theoretical study of the CVC has not yet been carried out. This is due to the lack of a formula for calculating the CVC, which, on the one hand, adequately reflects the non-stationary and unstable behavior of the $\mathrm{I}-\mathrm{V}$ characteristics in time, and, on the other hand, it is stable with respect to rounding errors in spatial variables. For the first time, a formula was derived in $[4,5]$ that allows one to calculate the theoretical CVC on the basis of a new mathematical model of processes occurring in an electromembrane system.

Consider the flow cell of the desalination of the electrodialysis apparatus. The Oy axis passes through the AEM, and the Ox axis perpendicular to it is directed toward the CEM. Let

\footnotetext{
* Corresponding author: angel_b@mail.ru
} 
the cell width be equal $H$ and the length - $L$. The current density at an random point in the cell at some point in time is denoted $\vec{I}(t, x, y)$. In [5-8], a 2D mathematical model of the main processes occurring in the desalination channel, namely, diffusion, electromigration, forced convection, and electroconvection, was formulated and researched in the form of a connected system of Nernst-Planck-Poisson and Navier-Stokes (NPPNS) equations with the corresponding boundary conditions, and the adequacy of these models was showed. To analyze the CVC formula, it is necessary to construct a basic electrical diagram of the desalination cell (Fig. 1). Equivalent electrical circuits were proposed in [9-10], and their use for studying impedance was considered. In [11], an equation was obtained for the impedance of a three-layer system consisting of an ion-exchange membrane and two adjacent diffusion layers. In these works, an attempt was made to use equivalent electrical systems as a model described by electrochemical equations. A flow cell is an open (open) electrical system with unique properties. Therefore, it should be considered as one of the basic and independent elements of the electric circuit, along with resistors, capacitors, etc. At the same time, to study some properties of the flow channel, simplified circuit diagrams can be built. We developed such a circuit diagram and used it to analyze the ratio of currents flowing in a circuit including a desalination channel and formulas necessary to derive the CVC.

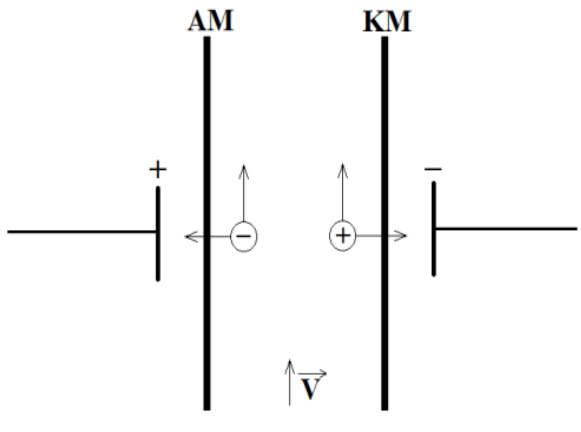

a)

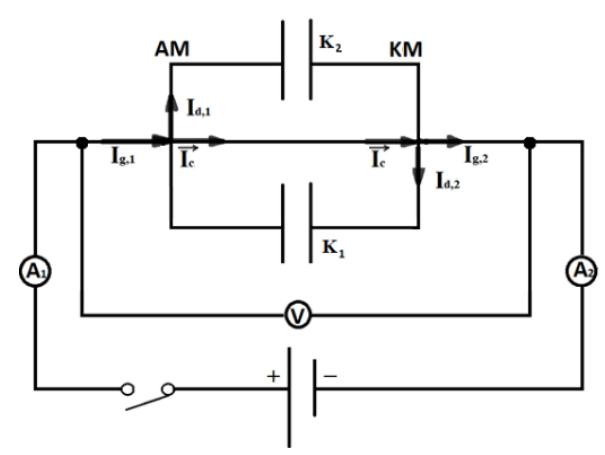

b)

Fig. 1. Scheme of a 2D image of a desalination cell in an electric circuit and its circuit diagram. Here $\mathrm{AM}$ is a AEM, KM is a CEM, the sign $\uparrow \vec{V}$ shows the direction of forced convection, the sign shows the directions of the possible movement of anions, the sign $\leftrightarrow \longrightarrow$ shows the directions of the possible movement of cations.

\section{Analysis of the CVC}

When analyzing the results of physical and numerical experiments [13-16], we found some data remain relatively unchanged, however, some of the data vary from experiment to experiment. If we restrict ourselves to experiments with a $\mathrm{NaCl}$ solution, then the diffusion coefficients of the cation and anion can be considered unchanged. The density of the solution and the kinematic viscosity coefficient, as well as the universal constants are considered to remain constant: the Faraday number F, the universal gas constant R, the absolute temperature $\mathrm{T}$, and the dielectric constant of the medium $\varepsilon$.

In the analysis of CVC, the Leveck limit diffusion current [11] is used.

Let us consider the point $x=0$. We show that, the total current is solenoidal, the bias current is potential (in principle, the current $\vec{I}_{c}(t, x, y)$ is not solenoidal or potential). 
From equations (1):

$$
\frac{\partial\left(z_{1} C_{1}+z_{2} C_{2}\right)}{\partial t}=-\operatorname{div}\left(z_{1} \vec{j}_{1}+z_{2} \vec{j}_{2}\right) \quad \frac{\partial \rho}{\partial t}=-\operatorname{div} \vec{I}_{c} .
$$

From (3) it follows

$$
\varepsilon_{a} \operatorname{div} \vec{E}=F\left(z_{1} C_{1}+z_{2} C_{2}\right)=\rho .
$$

Then

$$
\begin{gathered}
\varepsilon_{a} \frac{\partial}{\partial t} \operatorname{div} \vec{E}=-\operatorname{div} \vec{I}_{c} \quad \operatorname{div} \vec{I}_{c}=-\varepsilon_{a} \frac{\partial}{\partial t} \operatorname{div} \vec{E} \\
\operatorname{div} \vec{I}_{c}=-\varepsilon_{a} \frac{\partial}{\partial t} \operatorname{div} \vec{E}=-\frac{\partial}{\partial t} \rho(t, x, y)
\end{gathered}
$$

Where

$$
\begin{gathered}
\operatorname{div}\left(\vec{I}_{c}+\varepsilon_{r} \frac{\partial}{\partial t} \vec{E}\right)=0 \quad \vec{I}_{d, 1}=\varepsilon_{r} \frac{\partial}{\partial t} \vec{E} \\
\vec{I}_{g, 1}=\vec{I}_{c}+\vec{I}_{d, 1}
\end{gathered}
$$

We get $\operatorname{div} \vec{I}_{g, 1}=0$, i.e., $\vec{I}_{g, 1}(t, x, y)_{\text {- the solenoidal vector. }}$

On the other hand

$$
\vec{I}_{d, 1}=\varepsilon_{r} \frac{\partial}{\partial t} \vec{E}=-\varepsilon_{r} \frac{\partial}{\partial t} \nabla \varphi=-\varepsilon_{r} \nabla\left(\frac{\partial}{\partial t} \varphi\right)=-\varepsilon_{r} \nabla \psi,
$$

where $\psi=\frac{\partial}{\partial t} \varphi$.

Thus, $\vec{I}_{d, 1}=-\varepsilon_{r} \nabla \psi$ i.e. $\vec{I}_{d, 1}$ potential vector.

The corresponding relations for a point $x=H$ are proved in a similar way.

Given the fact that the vectors $\vec{I}_{g, 1}$ and $\vec{I}_{g, 2}$ are solenoidal, from the formulas

$$
\vec{I}_{g, 1}=\vec{I}_{c}+\vec{I}_{d, 1}, \quad \vec{I}_{g, 2}=\vec{I}_{c}-\vec{I}_{d, 2} \text { follows that } \operatorname{div} \vec{I}_{c}=-\operatorname{div} \vec{I}_{d, 1}=\operatorname{div} \vec{I}_{d, 2} \text {. }
$$

Hence,

$$
\frac{1}{2 H L} \int_{0}^{L H} \int_{0}^{H}(H-2 x) d i v \vec{I} d x d y=-\frac{1}{2 H L} \int_{0}^{L H} \int_{0}^{H}(H-2 x) d i v \vec{I}_{d, 1} d x d y=\frac{1}{2 H L} \int_{0}^{L H} \int_{0}^{H}(H-2 x) d i v \vec{I}_{d, 1} d x d y
$$

or 


$$
\frac{1}{2 H L} \int_{0}^{L} \int_{0}^{H}(H-2 x) d i v \vec{I}_{d, 1} d x d y=-\frac{\partial}{\partial t} \frac{1}{2 H L} \int_{0}^{L} \int_{0}^{H}(H-2 x) \rho(t, x, y) d x d y=-\frac{\partial}{\partial t} \hat{\rho}_{a v}(t)
$$

when

$$
\hat{\rho}_{a v}(t)=\frac{F}{2 H L} \int_{0}^{L} \int_{0}^{H}(H-2 x) \rho(t, x, y) d x d y=\frac{F}{2 H L} \int_{0}^{L} \int_{0}^{H}(H-2 x)\left(z_{1} C_{1}+z_{2} C_{2}\right) d x d y
$$

is a reduced average space charge density.

Thus, the first term $i_{a v}(t)$ in formula (3) is the averaged ohmic current carried by ions, and the value of the second term $i_{d}(t)$ is the averaged divergence of the bias current or the rate of change of the reduced average space charge density.
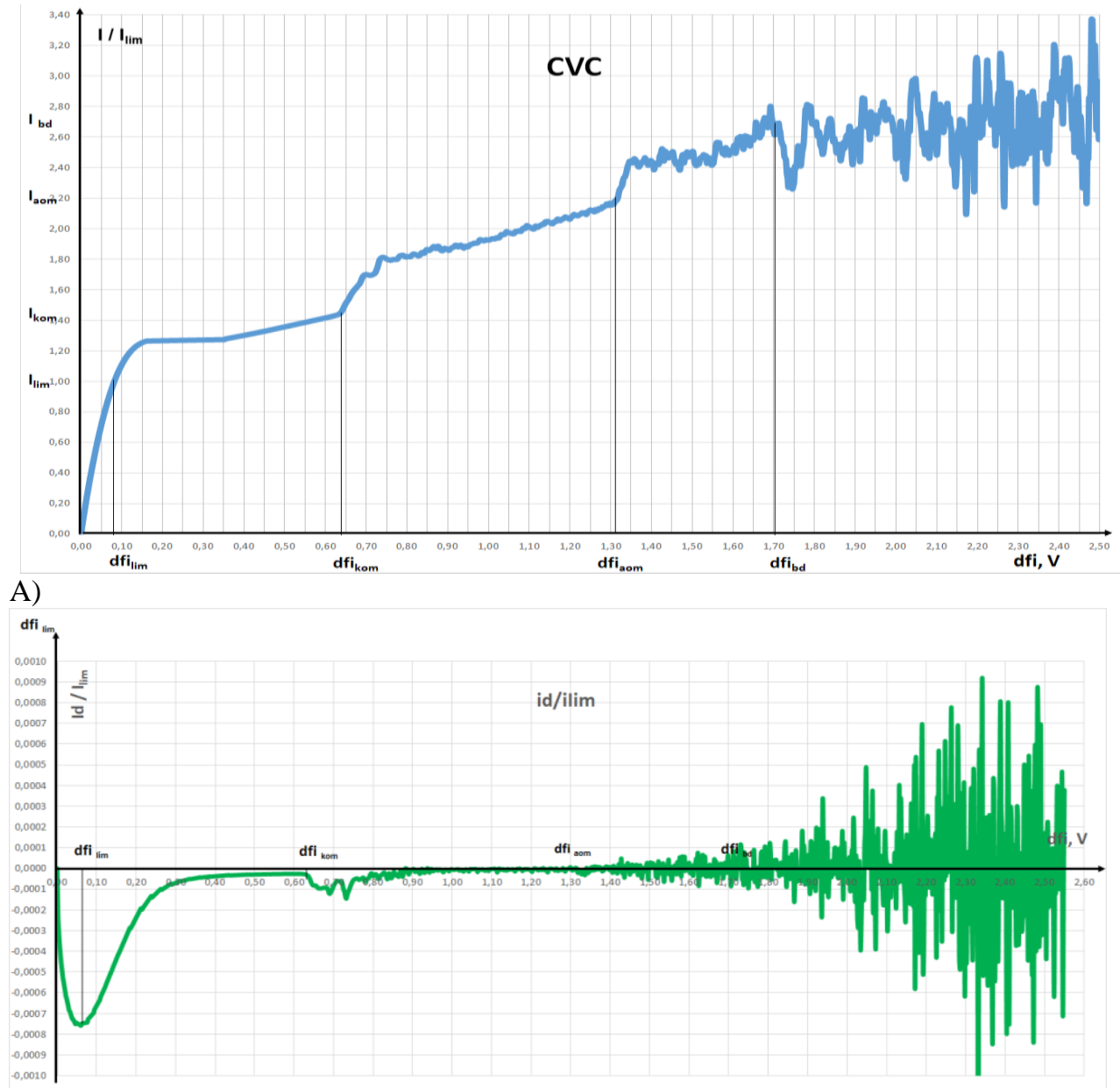

B)

Fig. 2. Graphs of currents $i_{a v}(t)$ and $i_{d}(t)$. 
Although the total current in the calculation of the CVC is not constant in time, its change can be considered to be slow. In this case, capacitors practically do not pass the electric current. Therefore, when calculating the CVC of the salt ion transport process, it is not necessary to take into account the bias current. In addition, the bias current does not need to be considered if the current-voltage curve of the conduction current $\vec{I}_{c}$ is investigated. In these cases, the CVC must be calculated via the formula:

$$
i_{a v}(t)=\frac{1}{H L} \int_{0}^{H} \int_{0}^{L} I_{x}(t, s, y) d y d s
$$

\section{The dependence of the CVC on the variable parameters}

The variable parameters that determine the experimental conditions are the width $\mathrm{H}$ of desalination cell, which usually varies from $0.5 \mathrm{~mm}$ to $10 \mathrm{~mm}$, depending on the size of the experimental cell; the cell length $\mathrm{L}$ ranging from $1 \mathrm{~mm}$ to tens of centimeters; the average rate of forced flow of the solution $V_{0}$ which is from 0 to $10 \mathrm{~cm} / \mathrm{s}$; the initial concentration $C_{0}$

0 of the solution is from the range $10^{-3} \mathrm{~mol} / 1$ to $1 \mathrm{~mol} / 1$. The potentiodynamic regime is considered and the potential jump varies from $d_{\varphi}=0{ }_{\mathrm{V} \text { to }} d_{\varphi}=3 \mathrm{~V}$.

Let's examine the dependence of the CVC on the cell length.

Analysis of the CVC for different cell lengths shows that, although the basic laws are preserved for the "short" cell, there is no clearly defined "plateau", the critical values of the potential jump are higher, and the current density is also higher everywhere except for the initial "ohmic" section. The CVC at $\mathrm{L}=2 \mathrm{~mm}$ and $\mathrm{L}=3 \mathrm{~mm}$ differ slightly.

We found an analogy between the behavior of the CVC during cell elongation and the behavior of the CVC with increasing potential jump.

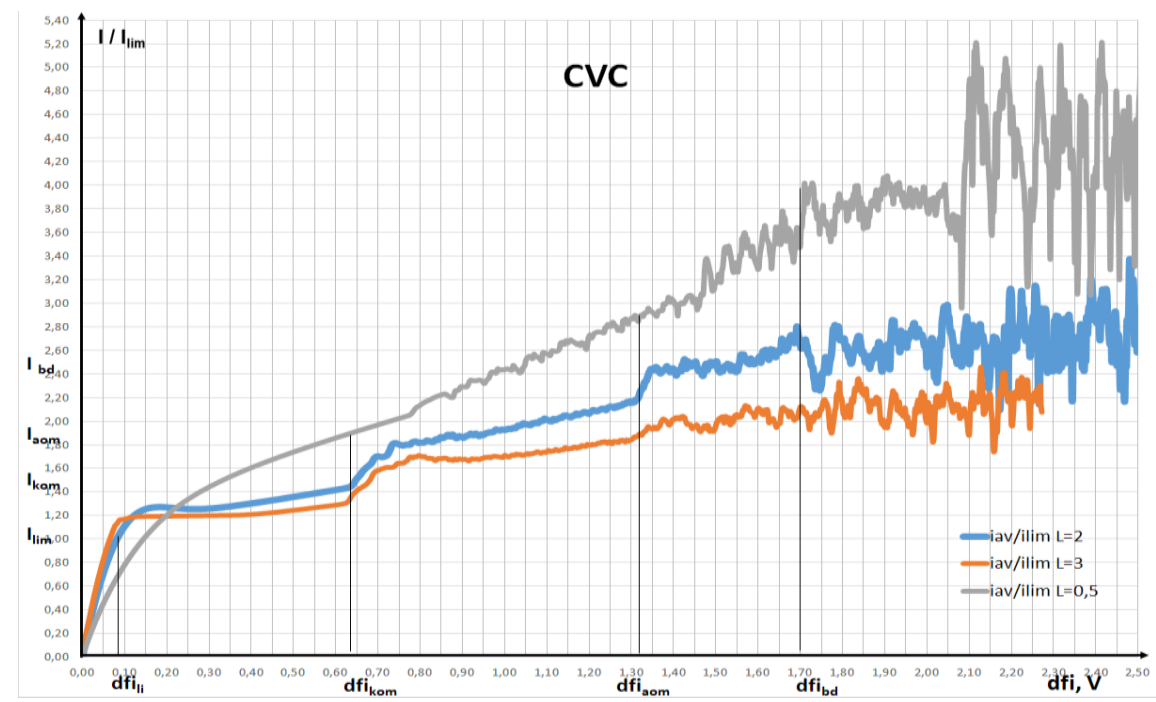

Fig. 3. Current-voltage curves at $\mathrm{H}=0.5 \mathrm{~mm}, \mathrm{~V} 0=0.1 \mathrm{~mm} / \mathrm{s}, \mathrm{C} 0=0.01 \mathrm{~mol} / \mathrm{m}^{3}$ and different cell lengths: "short" cell with $\mathrm{L}=0.5 \mathrm{~mm}$, "middle" cell $\mathrm{L}=2 \mathrm{~mm}$, "long" cell with $\mathrm{L}=3 \mathrm{~mm}$.

Let's examine the dependence of the CVC on the average solution speed 
It follows from Fig. 5 that although the CVC, although depends on the average solution speed, this dependence is small (see also [3-5, 13-16]).

Calculations show that the dependence of the CVC on the boundary concentrations $C_{a m}$ $C_{k m}$ is weak. This is obvious theoretically, since CVC is an integral characteristic, while boundary concentrations affect the solution of the boundary value problem corresponding to the mathematical model locally, only in a small neighborhood of the boundaries.

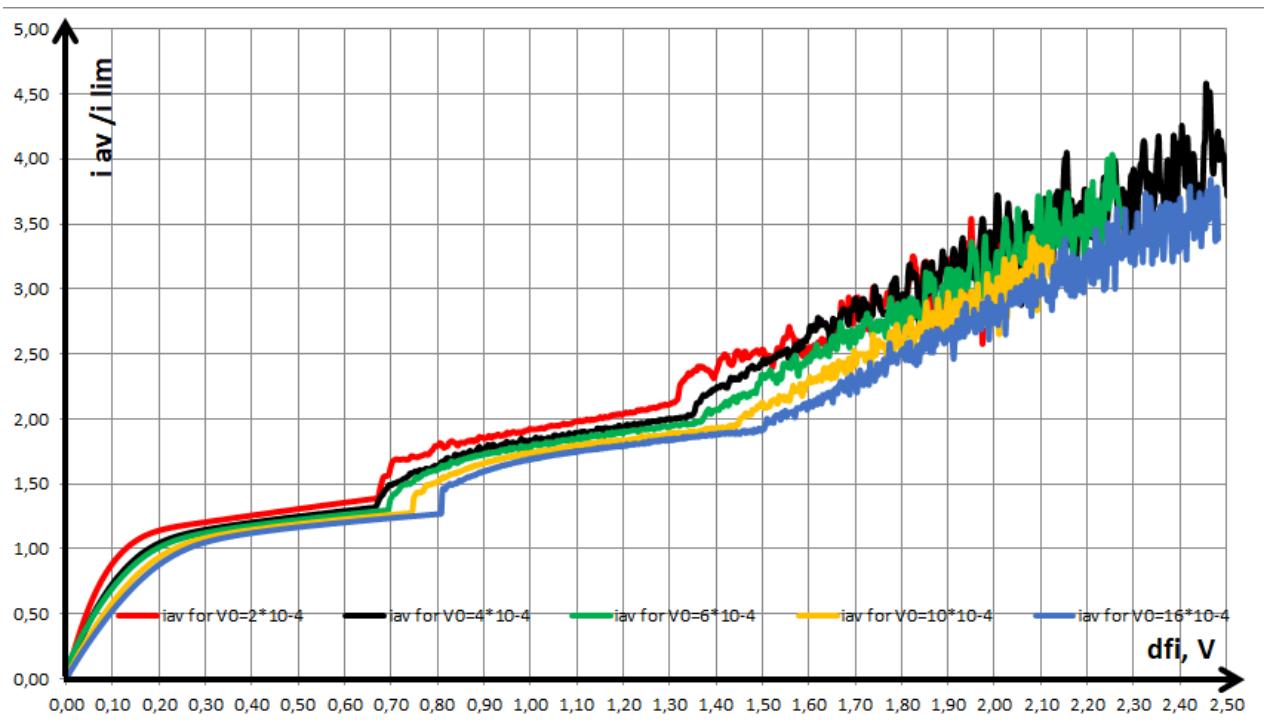

Fig. 4. Current-voltage curves at $C_{0}=0,01 \mathrm{~mol} / \mathrm{m}^{3}$ and different values of the solution speed.

Where: $V_{0}=2 * 10^{-4} \mathrm{~m} / \mathrm{s}, V_{0}=4 * 10^{-4} \mathrm{~m} / \mathrm{s}, V_{0}=6 * 10^{-4} \mathrm{~m} / \mathrm{s}, V_{0}=10^{-3} \mathrm{~m} / \mathrm{s}, V_{0}=1.6^{*} 10^{-3} \mathrm{~m} / \mathrm{s}$

\section{Acknowledgements}

The reported study was funded by RFBR according to the research project № 19-08-00252.

\section{References}

1. Budnikov E Yu 1999 Measuring Technique 11 40-44

2. Budnikov E Yu 2000 Analysis of fluctuation phenomena in the field of transcendental currents in an electro-membrane system Diss Cand Phys-Math $\mathrm{p} 115$

3. Kovalenko A V, Evdochenko E N and Urtenov M H 2015 Scientific journal KubSAU 05(109) 1-13 http://ejkubagroru/2015/05/pdf/66pdf

4. Urtenov M Kh, Kovalenko A V, Sukhinov A I, Chubyr N O, Gudza V A 2019 IOP Conference Series: Materials Science and Engineering Collection of materials of the XV International Scientific - Technical Conference Don State Technical University 012030 DOI: 101088 / 1757-899X / 680/1/012030

5. Urtenov M K, Uzdenova A M, Kovalenko A V, Nikonenko V V, Pismenskaya N D, Vasil'eva V I, Sistat P, Pourcelly G 2013 Journal of Membrane Science 447 190-202

6. Pham V S, Li Z, Lim K M, White J K, Han J 2012 Phys Rev E 86046310 
7. Kwak R, Pham V S, Lim K M, and Han J 2013 Phys Rev Lett 110114501

8. Druzgalski C L, Andersen M B, Mani A 2013 Phys Fluids 25(11) 110804

9. Randles J E B 1947 Discussions of the Faraday Society 111

10. Macdonald D D 2006 Electrochim Acta 511376

11. Nikonenko V V, Kozmai A E 2011 Electrochimica Acta 56 1262-1269

12. Zabolotsky VI, Nikonenko VV 1996 Ion transfer in membranes (M: Nauka) p 392

13. Nikonenko V V, Mareev S A, Pis'menskaya N D, Uzdenova A M, Kovalenko A V, M Kh Urtenov, Pourcelly G 2017 Russian Journal of Electrochemistry 53 1122-1144 DOI: 101134 / S1023193517090099

14. Nikonenko V V, Kovalenko A V, Urtenov M Kh et al 2014 Desalination http://dxdoiorg/101016/jdesal201401008

15. Uzdenova A M, Kovalenko A V, Nikonenko V V and Urtenov M H 2011 Condensed matter and phase interface 13(4) 317-24

16. Kovalenko A V, Urtenov M H, Pismenskiy V A, Nikonenko V V, Sisto F and Pismenskaya N D 2012 Electrochemistry 48(7) 830-42 